\title{
Contaminação do Lençol Freático pelo Vazamento de Óleo na Refinaria Presidente Getúlio Vargas - REPAR, Município de Araucária, Paraná
}

\author{
Clarissa Lovato Melo \\ 91570-970 PortoAlegre, RS - clamelo@bol.com.br \\ Artur Cezar Bastos Neto \\ Centro de Estudosem Petrologia e Geoquimica, IG, UFRGS - artur.bastos@ufrgs.br \\ Nelson Oswaldo Luna Caicedo \\ Instituto de Pesquisas Hidrológicas, UFRGS - caicedo@iph.ufrgs.br \\ Marcelo Ricardo Schwarz \\ Instituto de Geociências - UFRGS - pirita_rs@yaboo.com.br \\ Recebido: 12/12/01 - revisão: 05/08/02 - aceito: 06/12/02
}

Programa de Pós-Graduaşão em Geociências - Universidade Federal do Rio Grande do Sul - Caixa Postal 15001

\section{RESUMO}

Este trabalho apresenta os resultados da avaliação da contaminação na bacia do arroio Saldanha pelo vazamento de petróleo na Refinaria Presidente Getulio Vargas da PETROBRASS, Araucária, Paraná, ocorrido em 16 de julbo de 2000. O óleo atingiu o arroio Saldanha seguindo quatro fluxos distintos e, ao longo de sua extensão, extravasou o canal contaminando os banhados existentes, totalizando uma superficie contaminada de 17,70 hectares. A infiltração do óleo no subsolo ocorreu principalmente em duas áreas: 1) no entorno do scraper, onde se encontra a maior parte do óleo infiltrado (aproximadamente $43.000 \mathrm{~L}$ de óleo em fase livre); 2) no Banhado 4, onde o contaminante encontra-se, principalmente, adsorvido às particulas do solo. As características do primeiro favorecem a implantação de um sistema de drenagem subterrânea com recolbimento do óleo em caixas de coleta. No segundo, a inundação da área propiciaria a remoção de parte do contaminante por diferença de densidade e parte por uma barreira reativa para a qual o fluxo subterrâneo seria indųido.

Palavras-chave: vazamento de petróleo; contaminação; lençol freático.

\section{INTRODUÇÃO}

Um vazamento de cerca de quatro milhões de litros de petróleo ocorreu em 16 de julho de 2000 no oleoduto OSPAR na Refinaria Presidente Getúlio Vargas - REPAR, da PETROBRÁS, no município de Araucária, Região Metropolitana de Curitiba, Estado do Paraná (Figura 1). A partir do ponto de ruptura, o scraper (ponto de ligação do oleoduto com a refinaria) da REPAR, o óleo escoou por uma encosta e atingiu o arroio Saldanha. Ao longo dos 2,25 km de extensão deste arroio, o óleo extravasou o canal, contaminando uma série de banhados aí existentes, até chegar ao rio Barigüi, afluente do rio Iguaçu. O óleo foi contido cerca de $40 \mathrm{~km}$ à jusante, já no rio Iguaçu, no município de Balsa Nova. A área de estudo compreende desde o scraper até a foz do arroio Saldanha, sendo denominada, em seu conjunto, Ponto Zero. Os objetivos do estudo foram: 1) avaliar o grau de comprometimento do lençol freático, incluindo o cálculo do volume de hidrocarbonetos infiltrado no subsolo; 2) estimar o tempo para o contaminante infiltrado atingir, via fluxo subterrâneo, o rio Barigüi; 3) fornecer subsídios para a elaboração de um projeto de descontaminação.

\section{METODOLOGIA}

Os trabalhos de campo na área do Ponto Zero foram iniciados pela delimitação da superfície impactada (Figura 2) e pelo levantamento plani-altimétrico do seu entorno, resultando em quatro plantas na escala 1:500 e uma na escala 1:1000. Um total de 18 réguas linimétricas foi instalado nas drenagens da bacia do arroio Saldanha para medição dos níveis em diferentes condições pluviométricas.

Para o estudo do lençol freático, foram instalados e nivelados topograficamente 88 poços de monitoramento (PMs), com profundidade média de 2 a $3 \mathrm{~m}$. A leitura do nível d'água (N. A.) e a medida de espessura de óleo em fase livre foram efetuadas com medidor eletrônico de interface. Ensaios de permeabilidade nos PMs foram efetuados pelo método Slug Tests (Bouwer \& Rice, 1976) em 26 deles. Os dados obtidos nestes ensaios foram tratados com o aplicativo AQTESOLV (Dussield et al., 1989). O fluxo subterrâneo foi modelado pelo FLOWPATH II (Franz \& Guiguer, 1989) que fornece o padrão de escoamento (módulo e direção da velocidade de percolação) e a distribuição das cargas hidráulicas do freático. 
Os parâmetros de qualidade da água $(\mathrm{pH}$, temperatura, oxigênio dissolvido, turbidez, salinidade e condutividade elétrica) foram determinados em todos os PMs utilizandose um multimedidor HORIBA U10. A amostragem de água para análise química foi efetuada nos PMs sem óleo em fase livre, após esgotamento, utilizando-se um amostrador de polipropileno para cada amostragem. Os frascos com as amostras de água foram acondicionados em isopor com gelo até a entrega aos laboratórios para análise química. As análises de THP (Total de Hidrocarbonetos de Petróleo) foram realizadas com extração por n-hexano e a análise por CG-DIC (Cromatografia Gasosa - Detecção por Ionização em Chama). As análises de BTEX (Benzeno, Tolueno, Etilbenzeno, Xileno) foram efetuadas com extração por Purge \& Trap e análise por CG-EM (Cromatografia Gasosa - Espectometria de Massa).

A caracterização pedológica foi efetuada a partir das descrições dos perfis nas 88 locações de PMs, de 10 trincheiras efetuadas para amostragem contínua de solo com coleta em anéis metálicos e, também, de sete furos efetuados para amostragem para análise de contaminante. As análises de propriedades físicas e químicas do solo foram realizadas no Laboratório de Análises de Solo, Água e Resíduos, da UFRGS, sendo as análises químicas realizadas pelo método Walkley-Black com calor externo. As análises de THP no solo foram realizadas com extração por n-hexano e análise por CG-DIC. Os compostos BTEX no solo foram analisados pelo método Headspace-CG.

\section{CARACTERÍSTICAS FÍSICAS DA ÁREA}

Na área do Ponto Zero, as cotas máxima e mínima variam de $906 \mathrm{~m}$ próximo ao scraper, até $867 \mathrm{~m}$ na margem do rio Barigüi, caracterizando um desnível de $39 \mathrm{~m}$ a ser vencido nos $2.250 \mathrm{~m}$ de comprimento aproximado do arroio Saldanha. Isto implica num gradiente hidráulico de 1,73\%, considerado muito alto para o escoamento superficial.

O arroio Saldanha foi dividido em quatro segmentos distintos (Figura 2). O primeiro segmento, a jusante do ponto do acidente, é constituído por uma drenagem bem encaixada com cerca de $300 \mathrm{~m}$ de comprimento. O segundo segmento é formado por um banhado com extensão de $1000 \mathrm{~m}$ e largura de 20 a $100 \mathrm{~m}$. As equipes atuantes na área convencionaram subdividir este banhado em três partes ( $\mathrm{Fi}$ gura 2). O Banhado 1 tem seu limite inferior no aterro da estrada. O Banhado 2 estende-se deste aterro até as referências de nível (RNs) 06 e 07, onde ocorre o principal estrangulamento natural do banhado. O Banhado 3 estende-se daí até o local onde, de fato, termina o banhado natural. $\mathrm{O}$ terceiro segmento, constituído por um vale bem encaixado com direção NNW-SSE, estende-se por cerca de $400 \mathrm{~m}$, sem presença de banhados. O quarto segmento situa-se na planície de inundação do rio Barigüi, sendo denominado Banhado 4.

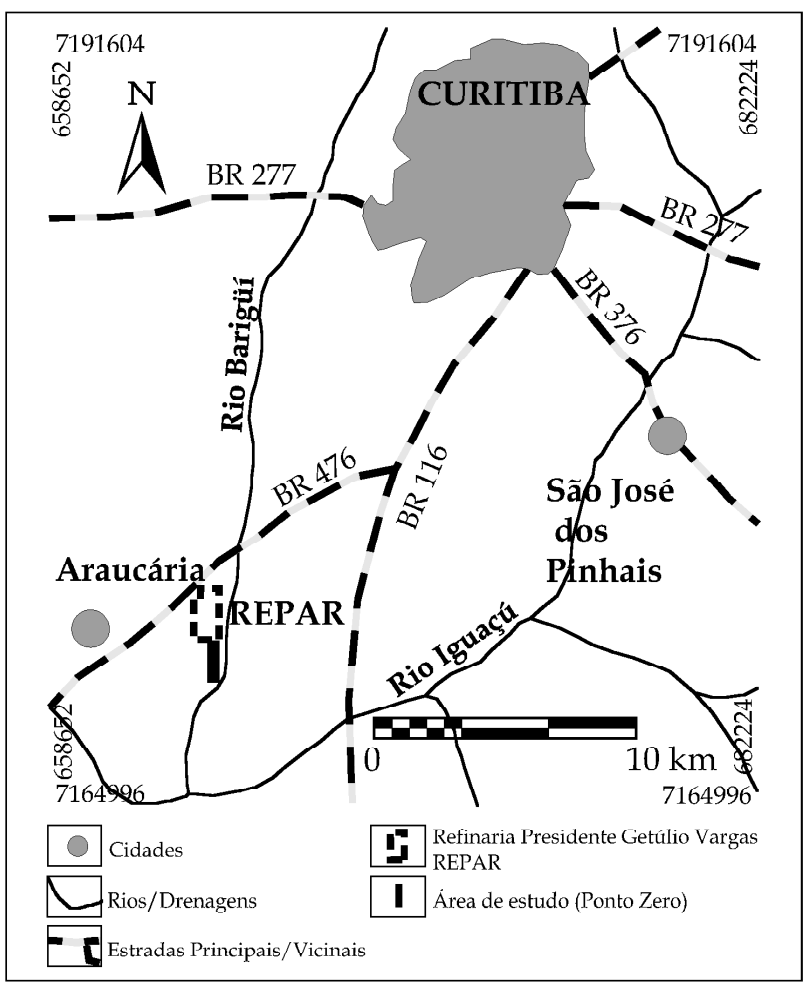

Figura 1. Localização da Refinaria Presidente Getúlio Vargas - REPAR.

Em condições pluviométricas normais, sem ocorrência de grandes precipitações, as vazões do arroio Saldanha nas estações RNs 02, 14 e 17 foram 1,86 L s' ${ }^{-1}, 2,77 \mathrm{~L} \mathrm{~s}^{-1}$ e 5,24 L s${ }^{-1}$, respectivamente. Em período chuvoso, obteve-se vazões dez vezes maiores.

As rochas existentes na região são gnaisses do Complexo Gnáissico-Migmatítico, sedimentos da Formação Guabirotuba e depósitos recentes (Figura 3). Na área de estudo, as rochas do Complexo Gnáissico são, principalmente, migmatitos com paleossomas de biotita-gnaisse e ocorrem muito alteradas. Estas rochas afloram em locais muito restritos e foram encontradas em algumas sondagens. Os sedimentos da Formação Guabirotuba ocorrem nas encostas da bacia do arroio Saldanha, onde são constituídos por argilas e, subordinadamente, areias de granulometria variada, com presença constante de matéria orgânica e óxidos de ferro associados. Nos banhados, ocorrem sedimentos aluvionares atuais. Nos Banhados 1 e 2 predominam sedimentos argilosos de cores variadas, sendo comuns grãos de quartzo e feldspatos de diversos tamanhos. A partir do Banhado 3, ocorre um aumento na quantidade de areia. No Banhado 4, areias finas e sedimentos argilosos ocorrem em iguais proporções.

A unidade de solo predominante na área é da classe dos Alissolos, porém, ao longo das drenagens, existe a formação de solos hidromórficos (banhados) da classe dos Gleissolos $\mathrm{Na}$ área de transição entre essas duas unidades, foi encontrado um perfil de Cambissolo associado a 
afloramento do embasamento. A classe dos Alissolos apresenta perfis característicos de solos minerais, com textura argilosa, horizonte A do tipo proeminente, bem desenvolvido, rico em matéria orgânica, sobre um horizonte B textural, de coloração avermelhada, argila de alta atividade, teores elevados de alumínio trocável, baixa saturação de bases trocáveis e elevada acidez. A classe dos Gleissolos compreende solos hidromórficos, constituídos por material mineral, que apresentam horizonte glei dentro dos primeiros $50 \mathrm{~cm}$ da superfície do solo ou a profundidades entre $50 \mathrm{e}$ $125 \mathrm{~cm}$. Neste último caso, os horizontes glei situam-se imediatamente abaixo de horizontes $\mathrm{A}$ ou $\mathrm{E}$, ou são precedidos de horizonte B incipiente, B textural ou C. Estes perfis encontram-se permanente ou periodicamente saturados por água, salvo se artificialmente drenados. A água de saturação ou permanece estagnada internamente, ou a saturação é por fluxo lateral no solo. Em qualquer circunstância, a água do solo pode se elevar por ascensão capilar, atingindo a superfície do mesmo. $\mathrm{Na}$ área mais plana no entorno do scraper existe um aterro com espessura de até $2 \mathrm{~m}$.

A profundidade do N. A. é pouco variável nos Banhados 1, 2, 3 e 4, onde as médias observadas foram, respectivamente, $0,81 \mathrm{~m}, 0,58 \mathrm{~m}, 0,53 \mathrm{~m}$ e $0,81 \mathrm{~m}$ (dados da campanha de monitoramento de outubro de 2000). Na encosta do scraper, a profundidade do N. A. situa-se entre 1,70 m e 2,80 m diminuindo gradualmente em direção aos banhados. $\mathrm{Na}$ parte leste da encosta, entretanto, mesmo nas cotas mais altas, a profundidade do N. A. é pequena, com valores entre 0,35 e $0,79 \mathrm{~m}$, o que se deve, provavelmente, à menor declividade desta vertente.

Os valores de condutividade hidráulica, obtidos em campo em metade dos ensaios de permeabilidade efetuados, são compatíveis com argilas. Os demais ensaios forneceram valores de condutividade hidráulica da ordem de 10-4 a $10-3 \mathrm{~cm} \mathrm{~s}^{-1}$, correspondendo a materiais como silte arenoso ou, eventualmente, areia. Os poços de monitoramento em que os ensaios de permeabilidade foram realizados podem ser observados nas Figuras 4 e 5. Observa-se, quanto à distribuição espacial dos resultados, que os valores mais baixos de condutividade hidráulica concentram-se na encosta do scraper e no Banhado 1. O Banhado 4 destaca-se como a área de maior condutividade hidráulica.

Para efeito da simulação do escoamento subterrâneo, a área foi subdividida em setor 1 (encosta do scraper e Banhados 1, 2 e 3) e setor 2 (Banhado 4). Tendo em vista que na região o nível d'água é raso, considerou-se os aqüíferos como livres e que o sistema de drenagem superficial representa a porção aflorante das águas subterrâneas, fixando-se, a partir das leituras das réguas, uma condição de contorno com carga hidráulica constante. No setor 1, atribuiu-se porosidade de $25 \%$, enquanto que no setor 2 , considerou-se porosidade de $25 \%$ nas áreas marginais elevadas e $40 \%$ na várzea. A partir do levantamento geofísico (BRAIM, 2000) posicionou-se a base da camada argilosa denominada Se-

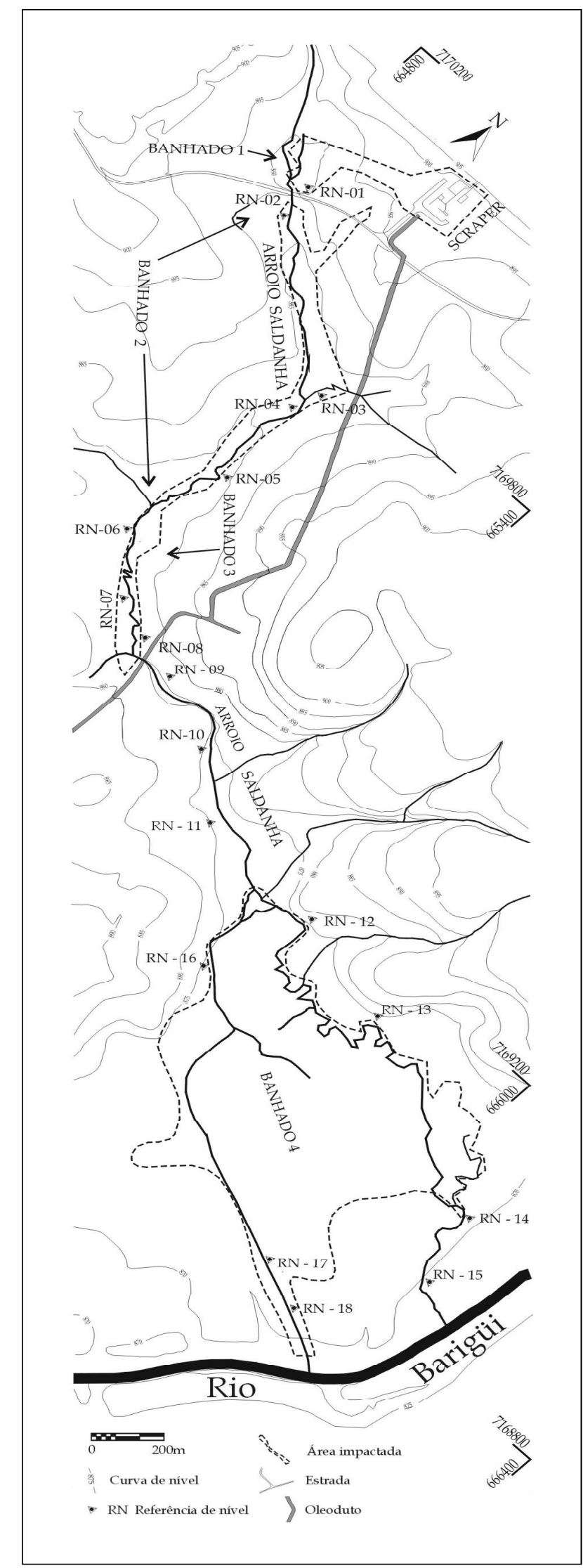

Figura 2. Bacia do arroio Saldanha. 
qüência 1, como o limite inferior do aqüífero. As condições de fluxo foram estabelecidas junto as maiores espessuras desta seqüência, que são verificadas nas porções centrais das drenagens da região. A diminuição dessas espessuras e eventualmente, seu desaparecimento na parte mais elevada das encostas, delimitam condições de não-fluxo. A calibragem da simulação foi efetuada comparando-se os resultados das cargas hidráulicas obtidas na simulação com aquelas observadas nos PMs e na drenagem superficial. $\mathrm{O}$ ajuste da simulação das condições de fluxo foi feito mantendo-se constantes todos os outros parâmetros do modelo e tornando variáveis as condições de recarga. $\mathrm{Na}$ encosta do scraper e Banhado 1, obteve-se velocidades lineares da ordem de $3 \mathrm{~m}^{2} \mathrm{ano}^{-1}$, atingindo, localmente, $8 \mathrm{~m}_{\text {ano }}{ }^{-1}$ As velocidades são sistematicamente maiores nos Banhados 2 e 3 , variando até $16 \mathrm{~m}_{\text {ano }}^{-1}$. O setor 2 é caracterizado pelas velocidades mais baixas na área do Ponto Zero; sendo inferiores a $1 \mathrm{~m}$ ano $^{-1}$ na parte contaminada do Banhado 4.

\section{CONTAMINAÇÃO DA ÁREA}

A área no entorno imediato do scraper foi toda coberta pelo óleo que, a partir daí, seguiu quatro fluxos superficiais distintos (Figura 4). O fluxo 1 deslocou-se pela encosta até atingir o Banhado 1. O fluxo 2 seguiu pela encosta, paralelamente ao acesso ao scraper, e interceptou a estrada geral, onde se somou ao óleo que foi canalizado pela estrada (fluxo 3). No local onde os fluxos se uniram, parte do óleo extravasou as margens da estrada e seguiu pela encosta, no rumo sul, sendo aqui considerado como uma continuação do fluxo 2 . O fluxo 3 foi canalizado pelo acesso ao scraper e, ao atingir a estrada geral, seguiu pela mesma até desviar-se para o arroio Saldanha, tanto a jusante como a montante do bueiro sob a estrada. O fluxo 4 foi, aparentemente, muito bem canalizado pela drenagem superficial, contaminando uma superfície extremamente pequena e atingindo o Banhado 2 já em sua parte intermediária

No Banhado 1, as marcas na vegetação indicaram que o óleo foi parcialmente represado, acumulando-se numa lâmina com até $0,50 \mathrm{~m}$ de espessura. Nos Banhados 2 e 3, o canal fluvial não foi suficiente para dar vazão ao óleo, ocorrendo extravasamentos. As marcas no solo indicam uma faixa de contaminação contínua (Figura 2).

No segmento entre os Banhados 3 e 4 o óleo foi totalmente canalizado. Ao atingir o Banhado 4, o óleo extravasou novamente o canal e espalhou-se na várzea. A superfície total contaminada foi de 17,70 ha, sendo: 1,20 ha no entorno do scraper e encosta; 3,0 ha no conjunto de Banhados 1, 2 e 3; e 13,5 ha no Banhado 4.

A presença de óleo em fase livre foi constatada principalmente nos PMs situados ao longo dos fluxos 1 e 2 e no Banhado 1 (Tabela 1). As maiores espessuras de fase livre, valores de até $23 \mathrm{~cm}$, concentraram-se nos PMs ao longo do fluxo 1, mais especialmente nos PMs nas partes superio-

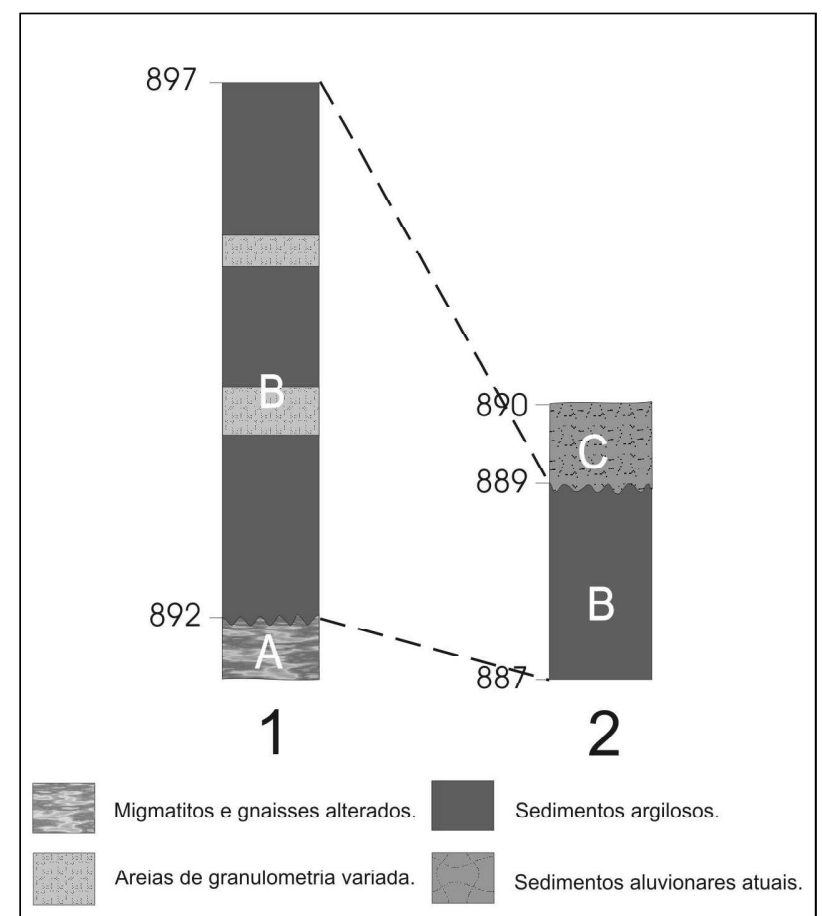

Figura 3. Seção litoestratigráfica representativa da área de estudo: 1 - perfil na encosta do scraper; 2 - perfil no Banhado 1. A - Complexo Gnáissico-Migmatítico; B - Sedimentos da Formação Guabirotuba; C - Sedimentos aluvionares.

res da encosta. Nas demais áreas, os valores máximos foram de $5 \mathrm{~cm}, 3 \mathrm{~cm}$ e $1 \mathrm{~cm}$, respectivamente, nos Banhados $1,2 \mathrm{e}$ 4. O cálculo do volume de óleo em fase livre foi efetuado com base no modelo de sistemas trifásicos que considera saturações simultâneas de óleo, ar e água na região da fase livre. Na utilização do modelo, foi seguido o protocolo de cálculo de Parker et al. (1996) que se baseia na equação de Van Genuchten (1980), ajustando curvas de retenção de forma parametrizada para sistemas bifásicos e extrapolando-as para um sistema trifásico. As curvas de retenção foram obtidas em laboratório a partir de ensaios específicos de tensão-saturação em panela de pressão. Os valores obtidos foram ajustados ao modelo de Van Genuchten (1980). Utilizaram-se os parâmetros, $\alpha$ (diâmetro médio dos poros do solo), m e n (distribuição do tamanho dos poros). O protocolo de cálculo de Parker et al. (1996), juntamente com o dimensionamento hidráulico do sistema de recuperação da fase livre, é objeto de um artigo em preparação. A presença de óleo em fase livre só é significativa na área englobando o scraper, fluxos 1 e 2 e Banhado 1, onde o volume total foi calculado em cerca de 43.000 litros, concentrando-se a maior parte do óleo nas partes mais próximas ao scraper.

A contaminação evidente da área torna redundante a apresentação das análises químicas de THP e BTEX efetuadas em amostras de solo e água. Os resultados, juntamente com a caracterização do óleo derramado, constam em Bastos Neto et al. (2000) e Meniconi et al. (2001). As 
análises de contaminante tiveram como objetivo principal distinguir os locais onde o óleo atingiu o freático, daqueles onde se encontra preferencialmente no solo e os possíveis controles sobre sua distribuição, visando orientar os trabalhos de remediação.

Os maiores teores de hidrocarbonetos no solo (com valores até $47.235 \mathrm{mg} \mathrm{kg}^{-1}$ ) foram obtidos nas amostras coletadas em banhados. As curvas de tensão-saturação indicam teores altos de saturação residual (da ordem de $30 \%$ ou mais), o que é uma característica dos solos com alto teor de argila que aumenta a retenção do contaminante. Altos teores de saturação residual são indicativos da dificuldade de entrada de ar e, conseqüentemente, de oxigênio para o solo, retardando, portanto, a degradação do contaminante. O teor de carbono orgânico foi bastante alto em algumas amostras, até $2,85 \%$, o que é um indicativo de maior potencial de retardo e retenção dos contaminantes menos móveis no solo. Fora dos banhados, constatou-se uma nítida tendência do contaminante concentrar-se no horizonte B do solo. A comparação de diferentes análises numa mesma amostra de solo indicou valores de BTEX significativamente menores do que os de THP, o que se explica pela facilidade com que os BTEX são lixiviados para a água e, também, por serem os compostos mais voláteis do óleo. Muito possivelmente, estes resultados se devem à presença dos HPAs (Hidrocarbonetos Policíclicos Aromáticos), em função de estes apresentarem alto coeficiente de retardo, muita afinidade com a matéria orgânica e baixa solubilidade e volatilidade. Desta forma, é possível inferir que há maior presença de HPAs no solo e de BTEX na água.

Segundo Van den Berg (1994), com valores STI, o valor de THP na água subterrânea para o Risco Máximo Permitido (RMP) é de $600 \mu \mathrm{g} \mathrm{L}{ }^{-1}$, considerando-se uma porcentagem de $10 \%$ de matéria orgânica e $25 \%$ de argila. Na área do Ponto Zero, os maiores valores $\left(188.334 \mu \mathrm{g} \mathrm{L}^{-1} \mathrm{e}\right.$ 95.605 $\left.\mu \mathrm{g} \mathrm{L}^{-1}\right)$ foram encontrados em amostras de água dos PMs do Banhado 1. As amostras dos PMs da encosta do scraper indicaram claramente a contaminação do freático, o que é coerente com a presença de fase livre na maioria dos PMs desta área. Já no Banhado 2, os valores de THP situaram-se entre $281 \mu \mathrm{g} \mathrm{L}{ }^{-1}$ e $38.830 \mu \mathrm{g} \mathrm{L}^{-1}$, distribuindo-se irregularmente nos 20 PMs aí instalados. No Banhado 3, duas das quatro amostras apresentaram valores de THP indicando a presença de contaminante. No Banhado 4 foram analisadas 37 amostras de água; o maior valor de THP encontrado foi de $9.351 \mu \mathrm{g} \mathrm{L}^{-1}$, seguido por $5.100 \mu \mathrm{g} \mathrm{L}^{-1}$; todas as demais amostras tiveram valores inferiores a $1.921 \mu \mathrm{g} \mathrm{L}^{-1}$; em 21 amostras a concentração foi inferior a $600 \mu \mathrm{g} \mathrm{L}^{-1}$.

Ainda em relação à água subterrânea, os compostos BTEX mostraram um panorama idêntico ao de THP: maiores concentrações na encosta do scraper e Banhado 1, diminuindo gradualmente em valores absolutos e freqüência de detecção em direção ao Banhado 4. A variação do $\mathrm{pH}$ de 5 a 7,3 pode estar associada a uma alta atividade de

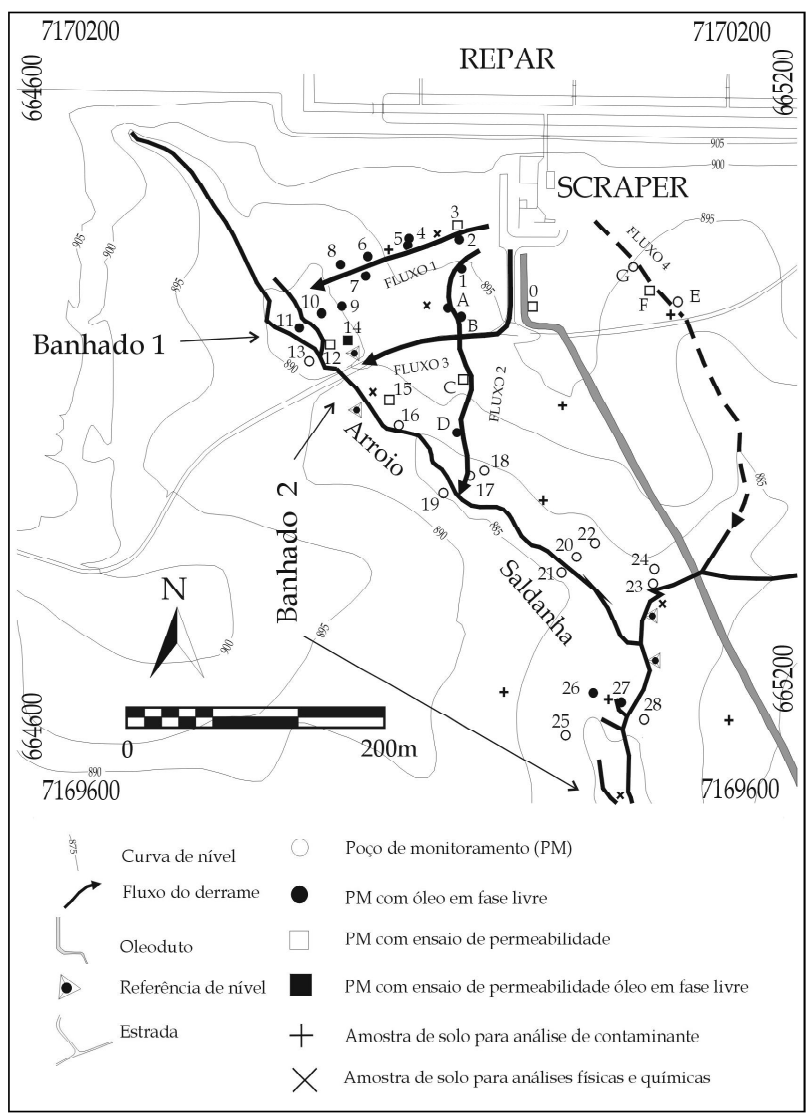

Figura 4. Mapa da área do scraper e parte superior do arroio Saldanha.

microorganismos, devido à elevada quantidade de matéria orgânica observada no local. O oxigênio dissolvido apresentou uma variação grande, de 0,04 a $4,5 \mathrm{mg} \mathrm{L}^{-1}$, mas não foi observada correlação com o grau de contaminação ou qualquer outro parâmetro, o que pode ser um indício de falta de adaptação da microfauna à contaminação. Por outro lado, é necessário considerar que outras reações ocorreram no solo e podem demandar o oxigênio dissolvido na água, como é o caso das reações de oxi-redução de alguns elementos químicos naturalmente presentes no solo.

\section{AVALIAÇÃO DOS RESULTADOS}

A superfície contaminada foi delimitada, desde as partes próximas ao scraper, de onde o óleo seguiu 4 fluxos distintos, até as áreas de banhados, onde o extravasamento dos canais principais acarretou no espalhamento lateral do óleo e contaminação das margens. A superfície contaminada totaliza 17,70 hectares, um valor bem abaixo da estimativa inicial.

No que tange à infiltração do óleo no subsolo e contaminação do freático, as quatro áreas do Ponto Zero foram caracterizadas por comportamentos muito distintos. Na primeira área, incluindo o scraper, os fluxos 1 e 2 e o Banhado 1 ocorreu a maior infiltração de óleo com o freático clara- 


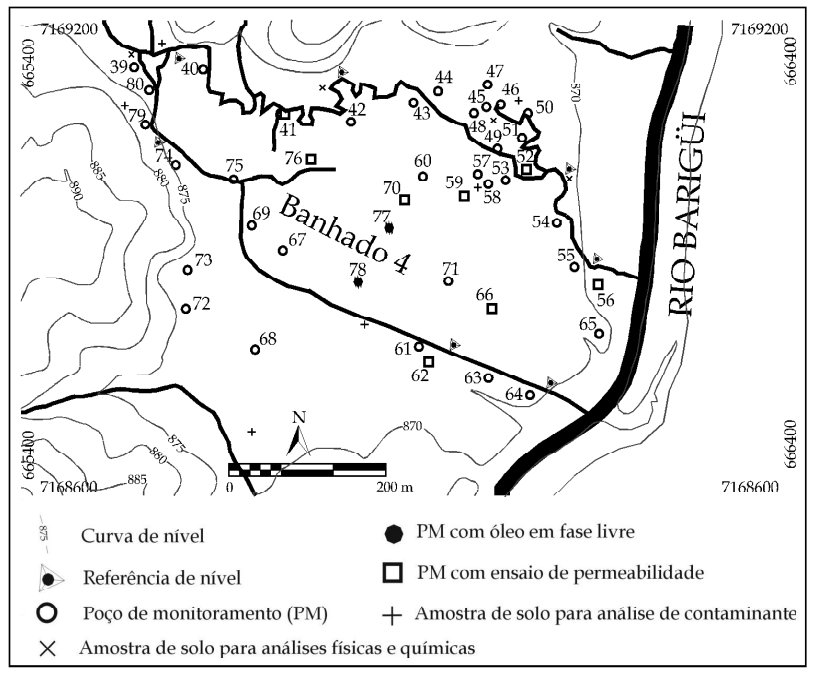

Figura 5. Mapa da área do Banhado 4.

mente contaminado. Observou-se uma relação direta entre a maior profundidade do N. A. e o volume de óleo infiltrado. No scraper e na encosta, onde o N. A. é mais profundo, infiltrou-se a maior quantidade de óleo; no Banhado 1, a menor profundidade do N. A. e, conseqüentemente, a maior saturação de água no solo, restringiu a infiltração de óleo. Por outro lado, em relação aos demais banhados, a infiltração no Banhado 1 foi grande, o que se deve, provavelmente, à alta pressão de carga associada ao barramento parcial do fluxo do óleo ocorrido neste banhado. A infiltração foi insignificante ao longo dos fluxos 3 (estrada compactada) e 4 (vertente leste, onde o N. A. é bastante raso).

$\mathrm{Na}$ segunda área, que inclui os Banhados 2 e 3, a contaminação do freático ocorreu de forma mais localizada. As características do solo e as baixas condutividades hidráulicas representaram um importante obstáculo à infiltração do contaminante que se encontra, em sua maior parte, adsorvido às partículas do solo. Os pontos onde o contaminante atingiu o freático não são conectados entre si e correspondem a locais isolados, onde a espessura da lâmina superficial de óleo foi maior, permitindo uma infiltração localizada de difícil quantificação.

A terceira área correspondente ao segmento do arroio Saldanha onde o vale é bem encaixado, o óleo foi bem drenado superficialmente e não se infiltrou no subsolo.

$\mathrm{Na}$ quarta área, correspondente ao Banhado 4, os extravasamentos dos dois canais principais acarretaram na contaminação de 13,5 hectares de solo. Constatou-se a ausência de fase livre na maioria dos PMs e as análises químicas da água forneceram, em mais da metade das amostras, concentrações de THP muito pequenas. O grande espalhamento lateral do óleo representou um fator restritivo à infiltração de grandes volumes, de modo que a maior parte do óleo infiltrado teria sido adsorvida às partículas do solo situadas acima do freático ou retida pela capilaridade. Por outro lado, as escavações efetuadas para remoção do
Tabela 1. Distribuição dos poços de monitoramento e presença de óleo em fase livre.

\begin{tabular}{lcc}
\hline Local & $\mathrm{n}^{\circ}$ de PMs & PMs com fase livre \\
\hline Fluxo 1 & 9 & 8 \\
Fluxo 2 & 4 & 3 \\
Fluxo 3 & 1 & - \\
Fluxo 4 & 3 & - \\
Banhado 1 & 5 & 3 \\
Banhado 2 & 20 & 2 \\
Banhado 3 & 4 & - \\
Banhado 4 & 42 & 2 \\
\hline
\end{tabular}

contaminante têm produzido óleo em fase livre. Esta aparente incoerência é explicada pelos valores de condutividade sistematicamente maiores do que os obtidos nos demais banhados. Esta característica do subsolo neste banhado implica numa grande mobilidade do contaminante. Assim, a infiltração de água pluvial e as oscilações do nível freático são capazes de promover a retirada de parte do óleo adsorvido, acarretando na formação de fase livre e contaminação do freático, o que explica a produção de óleo em parte das escavações. Por outro lado, sob o ponto de vista da descontaminação, esta mobilidade representa uma característica extremamente favorável para remoção do contaminante.

Quanto ao deslocamento do contaminante através do fluxo subterrâneo, a grande quantidade de dados gerados pela malha de PMs e pela geofísica permitiu que o modelamento deste fluxo fosse efetuado com uma margem de erro muito pequena. O tempo necessário para que o óleo infiltrado na área do scraper e Banhado 1 possa atingir, via fluxo subterrâneo, o rio Barigüi é da ordem de 50 anos, considerando-se apenas o transporte advectivo.

\section{CONCLUSÕES E RECOMENDAÇÕES}

No que tange à contaminação do freático, concluiu-se que as duas áreas críticas no Ponto Zero são a área do scraper, incluindo a encosta e o Banhado 1, devido à quantidade de óleo infiltrado (43.000 litros aproximadamente) e a área do Banhado 4, onde o óleo, inicialmente retido no solo, está sendo gradualmente mobilizado para o freático. Nestas duas áreas, o contaminante pode ser praticamente removido do subsolo, com exceção do óleo residual que se degradará naturalmente.

Para a área do scraper e Banhado 1, em função do gradiente hidráulico, associado à declividade do terreno e às profundidades do nível d'água observadas nos PMs, recomendou-se a implantação de um sistema de drenagem subterrânea seguindo, aproximadamente, as curvas de nível. Um ligeiro caimento da drenagem permitiria o recolhimento do óleo em caixas de coleta na extremidade mais baixa de cada 
drenagem. Para acelerar o processo de descontaminação, podem ser implementadas trincheiras para injeção de nutrientes/bactérias que acelerem a degradação do óleo.

$\mathrm{Na}$ área do Banhado 4, em função de características específicas, tais como terreno de banhado a ser preservado, superfície contaminada relativamente grande, contaminante alojado principalmente no solo, e boa mobilidade do contaminante, recomendou-se a inundação, restrita à área contaminada, com uma lâmina d'água centimétrica. Isto propiciaria a remoção do contaminante através da ascensão por diferença de densidade da fração leve do óleo e sua coleta na superfície. Um manejo adequado do banhado inundado permitiria a otimização da remoção do contaminante.

Nas áreas dos Banhados 2 e 3, a topografia plana e a baixa condutividade desfavorecem a implantação de sistema de drenagem por trincheiras e o deslocamento do óleo infiltrado em caso de inundação da área. Por outro lado, a infiltração ocorreu em locais restritos e em volumes muito reduzidos. Neste sentido, técnicas de reabilitação envolvendo a remoção do solo para descontaminação podem acarretar em mais danos do que benefícios. Recomendou-se, portanto, apenas a adição superficial de nutrientes que acelerem o processo de degradação do contaminante.

\section{AGRADECIMENTOS}

Ao gerente geral da UN-REPAR, engenheiro químico Rubens Novicki; ao coordenador do comitê do Rio Iguaçu, engenheiro químico Fernando Henrique Falkiewicz; ao engenheiro químico Ernani Zamberlan da Gerência de Saúde, Meio Ambiente e Segurança Industrial da REPAR; ao técnico de segurança Adolfo Muntch da REPAR; aos geólogos Nilo Azambuja e J. B. Françolin do CENPES; ao técnico em geologia Sérgio Quintão da PETROBRÁS.

\section{REFERÊNCIAS}

BASTOS NETO, A. C.; CAICEDO N. L. e MELO, C. L. (2000). Contaminação do lençol freático na área do Ponto Zero município de Araucária, Paraná. Relatório da fase de avaliação. Projeto IGEO/REPAR. UFRGS-FAURGS. 93p. Dezembro.

BOUWER, H. \& RICE, R. C. (1976). A slug test methods for determining hydraulic condutivity of unconfined aquifers with completely or partitially penetrating wells. Water Resources Research, vol.12, n³, p.423-428.

BRAIM CONSULTORIA E TECNOLOGIA (2000). Relatório de mapeamento geofísico através das técnicas GPR (2D e 3D) e tomografia elétrica. Identificação de seqüências estratigráficas e zona contaminada. PETROBRÁS/REPAR. Setembro.

DUSSIELD, G. M. \& RUMBAUGH III. J O. (1989). AQTESOLV - Aquifer Test Solver version 1.00. October 17.
FRANZ, T. \& GUIGUER, N. (1989). FLOWPATH Version $2.0-$ Two Dimensional Horizontal Aquifer Simulation Model. Waterloo Hydrogeologic Software.

MENICONI, M. F. G.; GABARDO, I. T.; KREUSH, A. C. H. \& DA SILVA, C. E. F. (2001). Hydrocarbon in groundwater samples of Araucaria ecosystem following a crude oil spill. First International Congress on Petroleum Contamination of Soils, Sediments and Water. Londres. August.

PARKER, J. C.; WADDILL, D. W. \& JOHNSON, J. A. (1996). UST corrective action technologies: engineering design of free product recovery systems (draft). EPA - Risk Reduction Engineering Laboratory. Cincinnati, Ohio.

VAN DEN BERG (1994). Human exposure to soil contamination: a qualitative and quantitative analyses towards proposals for human toxicological intervention values. (Partitially Revised Edition). National Institute of Public Health and Environmental Protection. Report number 725201011. January.

VAN GENUCHTEN, M. T. (1980). A closed-form equation for predicting the hydraulic conductivity of unsaturated soils. Soil Scince Society of America Journal, vol.44, p.892-898.

\section{Contamination of Groundwater by Oil Spill at the Presidente Getúlio Vargas Refinery, Araucária - Paraná}

\section{ABSTRACT}

This work presents an evaluation of the contamination in the Saldanha watershed caused by the oil spill at the Presidente Getulio Vargas Refinery belonging to PETROBRÁS, Araucária-Paraná, which occurred on July 16 2000. The oil reached Saldanha stream following 4 different paths and, throughout its extension overflowed the channel, contaminating the existing wetlands, totaling 17.70 ha of contaminated area. Oil infiltration occurred mainly in two areas: 1) at the area surrounding the scraper where most of the infiltrated oil 43,000 L of oil in free phase) was found. 2) at Wetland 4, where contaminant is mainly adsorbed to soil particles. The characteristics of sector 1 allow the implementation of a subsurface drainage system with oil separation by density difference. In sector 2 flooding the area would allow the recovery of part of the contaminant by density difference and by a reactive barrier induced by groundwater flow.

Key-words: oil spill; contamination; water table. 